\title{
Expression of cysLT1 and cysLT2 Receptor in Chronic Hyperplastic Eosinophilic Sinusitis
}

\author{
Yuhui Ouyang $^{1,3}$, Atsushi Kamijo ${ }^{1}$, Shin-ichi Murata ${ }^{2}$, Atsushi Okamoto ${ }^{1}$, \\ Shuichiro Endo ${ }^{1}$, Ryohei Katoh ${ }^{2}$ and Keisuke Masuyama ${ }^{1}$
} 'Department of Otorhinolaryngology, Head and Neck Surgery, Interdisciplinary Graduate School of Medicine and Engineering,
Faculty of Medicine, University of Yamanashi, ${ }^{2}$ Department of Human Pathology, Interdisciplinary Graduate School of Medicine and
Engineering, Faculty of Medicine, University of Yamanashi, Yamanashi 409-3898, Japan and ${ }^{3}$ Beijing Institute of

Otorhinolaryngology, Beijing Tongren Hospital, Beijing 100-730, China

Received September 15, 2009; accepted October 14, 2009; published online December 22, 2009

\begin{abstract}
Elevated production of cysteinyl leukotrienes (cysLTs) from sinus tissues and abundant sinus eosinophils are characteristic features of chronic hyperplastic eosinophilic sinusitis (CHS). CysLTs exert their action through G-protein-coupled receptors named cysLTs receptor type I (cysLT1R) and type II (cysLT2R). These expressions of cysLT receptors in the sinus mucosa have yet to be clarified and the relationship between eosinophilia and the expression of these receptors remains obscure. We compared the expressions of cysLT1R and cysLT2R in the sinus mucosa in patients with $\mathrm{CHS}$, non-eosinophilic chronic sinusitis (NECS), and control sinus tissues; and analyzed the correlation between the expression of CysLTRs and the presence of sinus eosinophils by immunohistochemistry and real-time PCR. A significantly higher percentage of eosinophils expressing cysLT2R protein was observed in patients with CHS compared with NECS and controls. In addition, cysLT2R mRNA expression in CHS was significantly higher than in NECS and controls. Furthermore, a positive correlation was observed between cysLT2R mRNA expression and the number of infiltrated eosinophils. In contrast, the cysLT1R mRNA expression did not differ significantly among these groups. The effect of cysLTs on sinus eosinophils may be mediated through the cysLT2R in patients with CHS. These results may suggest the therapeutic benefit of cysLT2R antagonists in CHS.
\end{abstract}

Key words: cysLT1R, cysLT2R, CHS, eosinophils

\section{Introduction}

Cysteinyl leukotrienes (cysLTs) are lipid mediators that not only stimulate potent contractile activity for bronchial smooth muscles but also exert proinflammatory actions both in the upper and lower airways. Those cysLTs act on target organs through specific receptors. Seven-membrane domain G-protein-coupled receptors, termed cysLT1 receptor (cysLT1R) and cysLT2 receptor (cysLT2R), have been

Correspondence to: Keisuke Masuyama, M.D., Ph.D., Department of Otorhinolaryngology, Head and Neck Surgery, Interdisciplinary Graduate School of Medicine and Engineering, Faculty of Medicine, University of Yamanashi, 1110 Shimokato, Chuo, Yamanashi 4093898, Japan. E-mail: mkeisuke@yamanashi.ac.jp cloned and characterized by pharmacological studies so far $[8,15,20,24]$. While cysLT1R binds LTD4 with high affinity and binds LTC4 and LTE4 with low affinity [15], cysLT2R binds to both LTC4 and LTD4 with equal affinity [11]. Both receptors have been described to be co-expressed in various tissues, though the distributions of these two receptors are likely to be slightly different. These differences in ligand-binding affinity and distribution of cysLT1R and cysLT2R suggest that they have different functions in vivo.

An elevated production of cysLTs from sinus tissues has been reported in chronic hyperplastic eosinophilic sinusitis (CHS) [23]. CHS is characterized by the accumulation of eosinophils, often concomitant with nasal polypsis (NP), and frequently associated with asthma. Higashi et al. 
[9] have shown that urinary LTE4 (U-LTE4) concentrations in subjects with aspirin-tolerant asthma (ATA) with CHS were higher than those in the patients with ATA with normal sinuses. Furthermore, a significant decrease in the U-LTE4 concentration was observed after endoscopic sinus surgery in those patients. These data indicate that sinus tissues may exhibit an overproduction of cysLTs and that might be indicative of relevance to eosinophilia.

CHS with NP is sometimes resistant to medical treatment and often recurs regardless of endoscopic sinus surgery, especially when tissue eosinophilia is prominent [6, 18]. Asthma, especially aspirin-sensitive asthma (ASA), is believed to be one of the risk factors responsible for nasal polyp recurrence [1]; however, the exact pathophysiology of recurrence is still unknown. In these cases, an elevated production of cysLTs has been suggested and the overproduction of cysLTs may alter the functional properties of sinus eosinophils, thus leading to persistent inflammatory changes of the sinus tissues, which are difficult to manage medically.

CysLT1R antagonists have been widely used in clinical practice and demonstrated to be effective in controlling airway symptoms of asthma and allergic rhinitis. Sousa et al. [22] have shown that the percentage of inflammatory leukocytes expressing cysLT1R was significantly elevated in the nasal mucosa of patients with ASA compared to ATA. This may explain the increased responsiveness of the target organs in these patients. However, the precise distribution and role of cysLT2R, as well as cysLT1R, has yet to be clarified in the sinus tissues.

The aim of this study is to examine the expression of cysLT1R and cysLT2R on sinus mucosa of a group of patients with CHS, a group with NECS, and healthy controls; and to investigate the relationship between cysLTR expression and eosinophilia.

\section{Materials and Methods}

\section{Tissue preparation and diagnosis}

Maxillary sinuse mucosal tissue was collected from 22 patients during endoscopic sinus surgery (ESS) procedures done in the Department of Otorhinolaryngology at Yamanashi University Hospital. For the control group, 5 subjects without chronic rhinosinusitis, who also underwent surgery due to facial trauma and nasal tumors, were recruited. Written informed consent was obtained from all patients to provide these tissue samples, and the study was approved by the Ethics Committee of the University of Yamanashi Hospital. Diagnosis of chronic rhinosinusitis (CRS) was based on the presence of symptoms longer than 12 weeks, consistent findings using rhinoscopy, a positive computed tomography, and physical examination. Asthma was diagnosed based on the presence of reversible airway obstruction $(\geq 12 \%$ increase in FEV1 in response to a bronchodilator) [23]. Five patients were given a diagnosis of asthma. One of the patients with asthma proved to have a history of severe bronchoconstriction and nasal symptoms after ingestion of nonsteroidal anti-inflammatory drugs.
The number of eosinophils per high-powered field $(400 \times)$ was counted 4 times, each at a different loci each time in 22 samples from the patients. Patients with an average number of eosinophils $>20$ per high-powered field were diagnosed as CHS, and those $<20$ per high-powered field were diagnosed as NECS. In the patients with chronic rhinosinusitis, 11 were CHS, and 11 were NECS. All patients with asthma were included in CHS. Very little eosinophil infiltration was observed in the control sinus tissue. Ages of the patients ranged from 17 to 77 (mean 53.5) years. None of the patients had taken oral or intranasal corticosteroids or LT antagonists for at least one month prior to surgery. Sinus mucosal specimens were immediately frozen in liquid nitrogen or frozen in O.C.T. compound and stored at $-80^{\circ} \mathrm{C}$ for RNA extraction; at the same time, samples were fixed in $10 \%$ formalin for immunohistochemistry.

\section{Immunohistochemistry}

Immunohistochemistry was performed, as described elsewhere [5]. Rabbit polyclonal anti-human cysLT1R (Cayman Chemical, Ann Arbor, MI, USA) and cysLT2R antibody (MBL, Nagoya, Japan) were used for immunohistochemical analysis. These antibodies showed no crossreactivity of staining. Conventional procedures were used for immunohistochemistry by the application of EnVision+ (Dako Corp., Carpinteria, CA, USA). The reaction product was detected with 3,3'-diaminobenzidine chromogen (DAB, Dako, Carpinteria, CA). The formalin-fixed and paraffinembedded sinus specimens were incubated with anticysLT1R (1:200) after pretreatment in a microwave oven $\left(10 \mathrm{~min}\right.$ at 350 watt $90^{\circ} \mathrm{C}$ ) in citrate buffer and with 0.25 $\mu \mathrm{g} / \mathrm{mL}$ trypsin (for $10 \mathrm{~min}$ at $37^{\circ} \mathrm{C}$ ). The sections were photographed by digital color-CCD camera (Olympus BX50, Tokyo, Japan). Then, the sections were stained with hematoxylin-eosin (H\&E), and were photographed again at the same areas on the biopsies. For cysLT2R, the specimens were initially stained with $\mathrm{H} \& \mathrm{E}$, and subsequently photographed. After destaining of the H\&E, the sections were incubated with cysLT2R polyclonal antibody $(1: 20)$ after pretreatment using an autoclave $\left(20 \mathrm{~min}\right.$ at $\left.120^{\circ} \mathrm{C}\right)$ [12]. The immunohistostained samples were photographed again at the same areas on the biopsies. The specificity of the cysLT1R and cysLT2R antibody was investigated with the staining used normal rabbit immunoglobulin (Dako) of the same paraffin-embedded tissues. The numbers of eosinophils expressing cysLT1R and cysLT2R were objectively counted by comparison of the image of the $\mathrm{H} \& \mathrm{E}$ and immunostaining of cysLT1R and cysLT2R at the same areas on the biopsies.

\section{$R N A$ extraction and real time-PCR analysis}

Total RNA was extracted from the sinus biopsy specimens by using an RNeasy Mini kit (QIAGEN), then treated with TURBO DNase (Ambion) for $60 \mathrm{~min}$ at $37^{\circ} \mathrm{C}$. The treated total RNA was reverse-transcribed with a SuperScript First Strand System (Invitrogen) according to the manufacturer's instructions. Real-time PCR was performed 


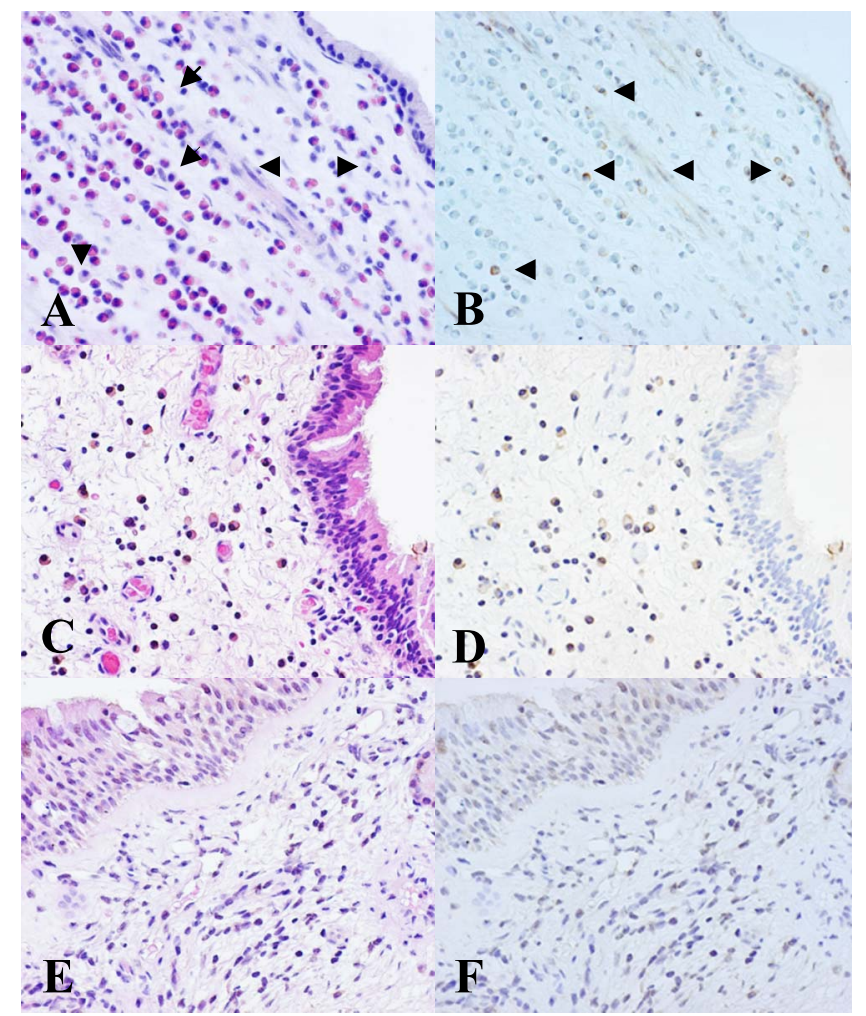

Fig. 1. Immunohistochemical staining of CysLT1R in the human sinus mucosa. H\&E staining and CysLT1R immunohistochemical staining in chronic hyperplastic eosinophilic sinusitis (CHS) (A, B), noneosinophilic chronic sinusitis $(\mathrm{NECS})(\mathbf{C}, \mathbf{D})$ and control tissues (E, F) respectively. A, $\mathbf{C}$, and $\mathbf{E}$ were stained by $\mathrm{H} \& \mathrm{E}$ after immunohistostaining with anti-CysLT1R antibody (B, D and F). CysLT1R-positive cells, which are marked by arrowheads, are plasma cells, neutrophils and vascular endothelial cells. Eosinophils expressed little CysLT1R immunoreactivity. Magnification $\times 400$.

with the ABI Prism 7500 Sequence Detection System (Applied Biosystems). PCR reactions contained $40 \mathrm{ng}$ cDNA of samples, 1X Taqman Universal PCR Master mix (Applied Biosystems), $200 \mathrm{nM}$ of primer pairs, and $250 \mathrm{nM}$ of TaqMan probe in a final volume of $25 \mu \mathrm{l}$. PCR protocol consisted of 1 cycle at $95^{\circ} \mathrm{C}$ for $10 \mathrm{~min}$ followed by 50 cycles at $95^{\circ} \mathrm{C}$ for $15 \mathrm{~s}$ and at $60^{\circ} \mathrm{C}$ for $1 \mathrm{~min}$. Genespecific primers and probes were purchased from Applied Biosystems. The primers and probes for the cysLT1R, (5'TGGATGAAACAGGAAATCTGACAGT, 5'-TACAAGG TGGAATACACTTGATTGC, and 5'FAM-CTGCCACAT GCCATGACACTATTGAT-TAMRA-3'), cysLT2 (5'-TAT TTCCTGACCGTGCTGAGTGT, 5'-TGACATCAGAAGCC GAAAG， 5'FAM-TGCGTTTCCTGGCAATGGTTCACCTAMRA-3') were used, and $\beta$-actin primer/probe pair (Applied Biosystems) was used as an internal control gene. The threshold cycle (CT) was recorded for each sample to reflect the mRNA expression levels. The relative cysLTR gene expression was determined by the $\mathrm{d} C T$ value method as described previously [14].

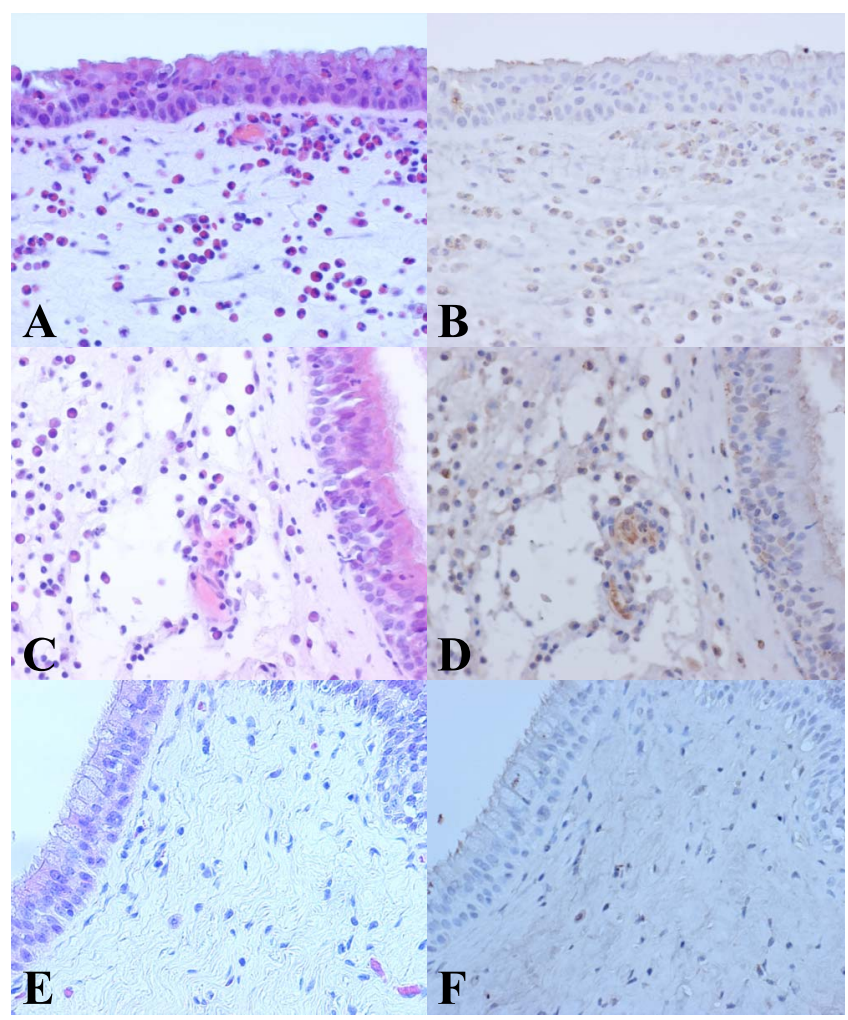

Fig. 2. Immunohistochemical staining for CysLT2R in the human sinus mucosa. H\&E staining and CysLT2R immunohistochemical staining in patients with CHS (A, B), NECS $(\mathbf{C}, \mathbf{D})$ and control tissues $(\mathbf{E}, \mathbf{F})$ respectively. B, D, $\mathbf{F}$ were immunohistostained with cysLT2R after staining and destaining of $\mathrm{H} \& \mathrm{E}(\mathbf{A}, \mathbf{C}$, and $\mathbf{E})$. Staining was observed mainly on eosinophils. Magnification $\times 400$.

\section{Statistical analysis}

Statistical analysis was performed using the SPSS version 11.0 software program for Windows (SPSS Inc., Tokyo, Japan). Correlations between cysLTRs expression and the eosinophil counts were evaluated by Pearson's correlation coefficient test using the SPSS statistical analysis software package. Between-group comparisons were performed using the Mann-Whitney $U$ test. Differences were considered to be significant at $P$ values equal to or less than 0.05 .

\section{Results}

\section{Immunohistochemistry}

Figure 1 and Figure 2 demonstrate the examples of immunohistochemical staining for cysLT1R and cysLT2R in CHS, NECS, and controls. The immunoreactivity for cysLT1R in the sinus mucosa was significantly detected in the vascular endothelial cells, plasma cells, neutrophils, and lymphocytes (Fig. 1B, D and F). In contrast, cysLT2R immunoreactivity was mainly detected in inflammatory cells, such as eosinophils, neutrophils, plasma cells, and lymphocytes (Fig. 2B, D and F), and was only slightly detected in the submucosal glands. However, the epithelial cells ex- 


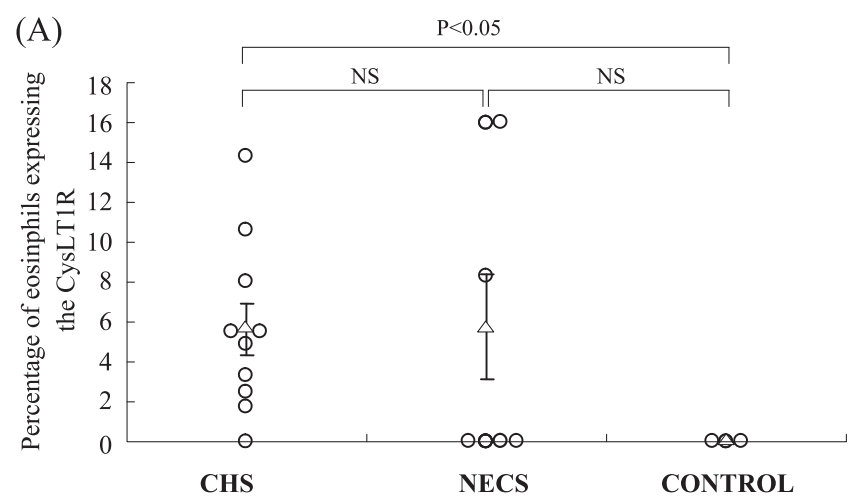

(B)

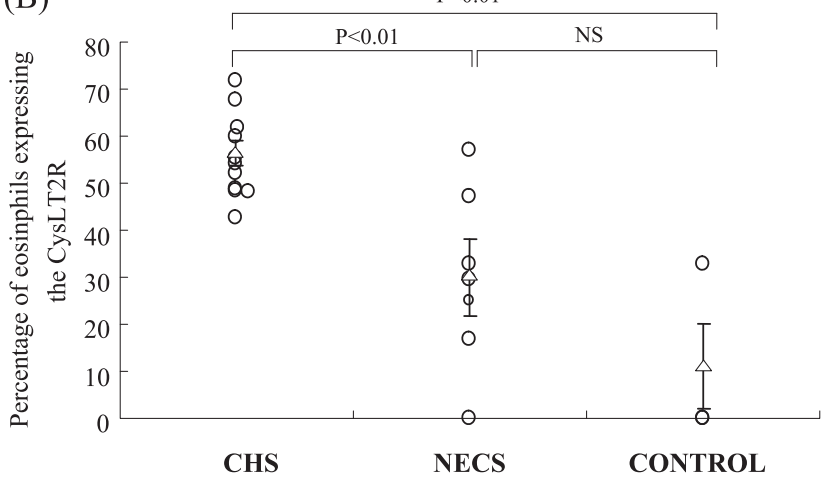

Fig. 3. Percentages of eosinophils expressing CysLT1R (A) and CysLT2R (B) in patients with CHS $(n=10)$, NECS $(n=7)$ and controls $(n=3)$. A significantly elevated percentages of eosinophils expressed CysLT2R in the patients with CHS compared with NECS and controls. There was no significant difference in the percentages of eosinophils which expressed CysLT1R in the patients with CHS compared with NECS. Mann-Whitney U test. NS, not significant.

pressed little or no cysLT1R or cysLT2R immunoreactivity. The specificities of cysLT1Rand cysLT2R antibodies using paraffin-embedded tissues were confirmed by the absence of staining with normal rabbit immunoglobulins (data not shown).

The percentages of eosinophils expressing cysLT1R or cysLT2R were compared within the subjects with CHS, NECS, and controls (Fig. 3). CHS patients showed a significantly elevated percentage of eosinophils expressing cysLT2R compared with those with NECS $(\mathrm{P}=0.006)$ and controls $(\mathrm{P}=0.01)$ (CHS: median, 56.3; range, 42.6-72; NECS: median, 29.8; range, 0-57.0; controls: median, 11; range, 0-33) (Fig. 3B). These eosinophils also showed a significantly elevated cysLT1R expression compared to controls $(\mathrm{P}=0.02)$, although no significant differences were observed between the percentages of eosinophils expressing cysLT1R in patients with CHS and NECS $(\mathrm{P}=0.62)$ (CHS: median, 5.67; range, 0-14.3; NECS: median, 5.75; range, 0-16.0; controls: median, 0) (Fig. 3A). In addition, there was no significant differences in the amount of eosino-
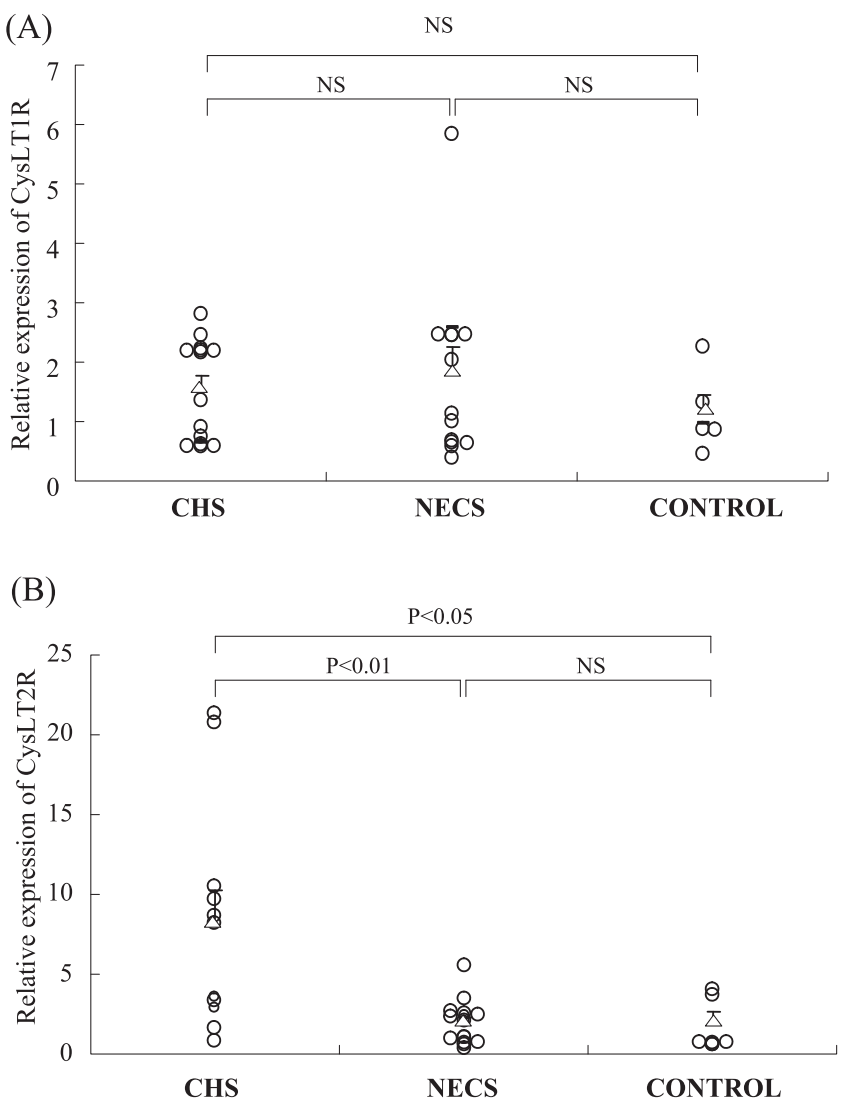

Fig. 4. Relative expression of CysLT1R (A) and CysLT2R (B) mRNA in CHS $(n=11)$, NECS $(n=11)$, and controls $(n=5)$. Expression of CysLT2R showed a significant increase in CHS patients compared to NECS and controls. Between NECS patients and the controls, there was no significant difference. However, the expression of CysLT1R was not significantly different among the three groups. Mann-Whitney U test; NS, not significant.

phils expressing both cysLT1R and cysLT2R between asthmatics and non-asthmatics.

\section{Real-time PCR analysis}

The expression of mRNA for cysLT1R and cysLT2R was analyzed by quantitative real-time PCR. The median relative expression levels of cysLT2R mRNA were 8.30 in CHS, 1.95 in NECS, and 1.90 in controls. A significantly higher expression level of cysLT2R mRNA was observed in subjects with CHS compared to those with NECS $(\mathrm{P}=0.006)$ and controls $(\mathrm{P}=0.047)$. Between the NECS and control groups, there was no significant difference in cysLT2R mRNA expression levels $(\mathrm{P}=0.69)$ (Fig. 4B). However, the median relative expression levels of cysLT1R mRNA were not significantly different among these three groups (1.52 in CHS, 1.80 in NECS, 1.17 in controls) (Fig. 4A).

Furthermore, a significant correlation was found between the relative expression levels of cysLT2R mRNA and the eosinophil counts in the sinus mucosa $(\mathrm{R}=0.651$, $\mathrm{P}=0.0002$ ) (Fig. 5B). However, there was no correlation 
(A)

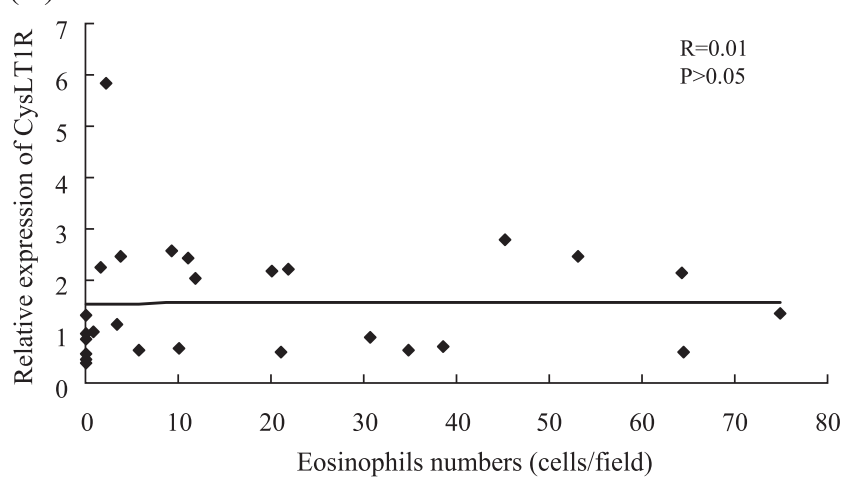

(B)

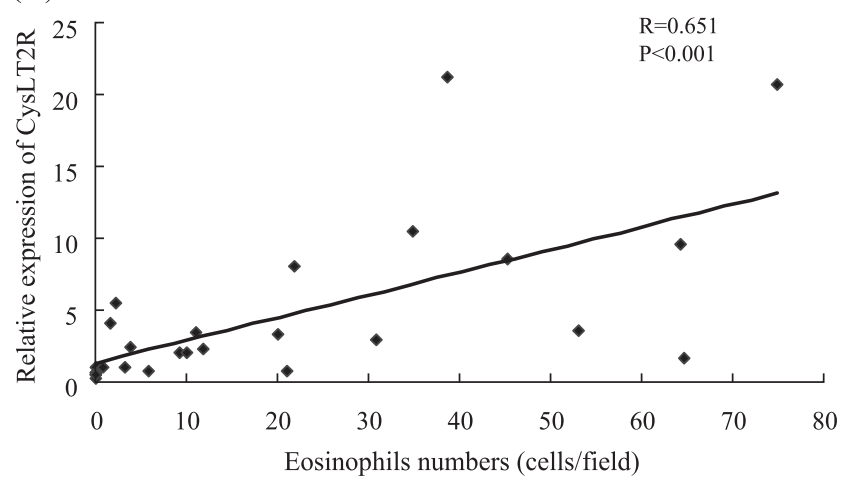

Fig. 5. The correlation between the number of eosinophils and the expression of CysLT1R (A), and CysLT2R (B) in all of the patients. The relative expression of CysLT2R correlated with the number of eosinophils in the sinus mucosa, whereas the relative expression of CysLT1R did not correlate with the number of eosinophils.

between cysLT1R mRNA and the number of eosinophils in the sinus mucosa $(\mathrm{R}=0.001, \mathrm{P}=0.96)$ (Fig. $5 \mathrm{~A})$.

\section{Discussion}

This immunohistochemical study demonstrated that elevated expression of cysLT2R on sinus mucosal eosinophils is confined to patients with CHS. In addition the eosinophils showed no evidence of upregulation of cysLT2R in patients with NECS compared to controls. In contrast, no elevated expression of CysLT1R in sinus eosinophils was found in patients with CHS in comparison to those with NECS.

The real-time PCR study has confirmed that cysLT2R expression is elevated in the sinus mucosa in patients with CHS compared with NECS. Furthermore, a positive correlation between the sinus mucosal cysLT2R mRNA and sinus eosinophil counts was observed but not between cysLT1R mRNA and the number of sinus eosinophils. These results are consistent with a previous study showing that CysLT2R transcript expression is higher in eosinophils than in basophils and neutrophils [10]. In addition, peripheral blood eosinophils have demonstrated relatively high expression of cysLT2R mRNA compared to cysLT1R [16]. Another study showed upregulation of cysLT2R protein on eosinophils in nonatopic asthma patients during asthma exacerbation, suggesting a modulatory role of cysLT2R on eosinophils in upper and lower airway inflammatory diseases [7]. The mechanisms of preferential elevation of cysLT2R expression on sinus eosinophils compared to cysLT1R in CHS remain to be clarified.

Sinus tissues are considered to be one of the main tissues that produce cysLTs. Steinke et al. [23] have demonstrated that a higher concentration of cysLTs is observed in sinus tissues obtained from patients with CHS than in healthy sinus tissues and noneosinophilic sinus tissues. In addition, Higashi et al. [9] have shown that urinary LTE4 (U-LTE4) concentrations, which are considered to be the most reliable parameter for monitoring the endogenous synthesis of cysLTs, in subjects with AIA with CHS were higher than those in the patients with ATA with normal sinuses. Furthermore, a significant decrease in the U-LTE4 concentration was observed after endoscopic sinus surgery in those patients. These sinus sections revealed a diffuse and marked infiltration of eosinophils, thus suggesting eosinophils might be a major source of leukotrienes (LTs) in the sinus tissues. These findings indicate that sinus tissues abundant in eosinophils may play a role even in CHS without asthma.

Two receptors for the cysLTs, termed the type I and type II cysLT receptors (cysLT1R and cysLT2R, respectively), have been identified and characterized [8, 15, 20, 24]. The cysLTs exert their actions through these specific receptors and are known for their powerful bronchoconstriction activity and their role in exacerbation of asthma. For these reasons, cysLTs receptors have been examined mainly in asthma patients. Previous reports have suggested that cysLT1R is upregulated in ASA compared to ATA [4, 22]. However, there was no upregulation of cysLT1R in CD45+ cells observed between nonaspirin-sensitive asthma and controls [4]. Accordingly, cysLT1R upregulation might be confined to ASA. In this report, the immunohistochemial study has shown that both cysLT1R and cysLT2R were upregulated compared to controls in CHS. Maxillary sinus mucosa was obtained and compared between the groups, thus demonstrating that few inflammatory cells were present in control sinus mucosa. This may explain why differences could be detected between CHS and controls.

CysLT1R antagonists have been recognized as highly effective and are widely used for allergic diseases such as asthma and allergic rhinitis $[3,17,19]$. In addition, the efficacy of cysLT1R antagonists (montelukast) in the treatment of nasal polyposis has recently been reported [13]. In that study, montelukast therapy improved nasal symptom scores in about $70 \%$ of patients. However, $30 \%$ of patients remained the same or worsened and it was likely to be more effective in the patients with perennial allergies. These reports imply that cysLT1R may be more related to the pathophysiology of allergies in the nose rather than the sinus diseases. Shirasaki et al. [21] have clearly demonstrated cysLT1R expression on vascular endothelial cells and inflammatory cells such as eosinophils, mast cells, and macrophages in the 
nose. Although nasal tissues have not been examined, the upregulation of cysLT2R in the sinus tissues in this study would suggest a different role of cysLTs in the sinus diseases and may partly explain why a cysLT1R antagonist is less effective in some of the patients with nasal polyposis.

The mechanisms of low level expression of cysLT1R on eosinophils compared with cysLT2R within sinus mucosa in CHS remain obscure. Interferon-gamma (IFN- $\gamma$ ) has been shown to upregulate cysLT2R expression on peripheral blood eosinophils in nonatopic patients, but with no effects on cysLT1R expression [7]. Furthermore, the cysLT2R expression on eosinophils has been shown to be upregulated during an exacerbation of asthma in nonatopic subjects, but not in atopic patients. In remission, the expressions of eosinophil cysLT1R and cysLT2R have been shown to be downregulated. Airway inflammation by viral infection such as rhinovirus is one of the triggers of asthma exacerbations, which may be accompanied by leukocytes trafficking and production of cysLTs and IFN- $\gamma$. It is likely that sinus eosinophils are modulated through viral infections and show preferential expression of cysLT2R rather than cysLT1R. Another recent study has demonstrated that cysLT2R may play a role in airway remodeling in mice [2]. Further studies will be needed to determine whether cysLT2R can play a role in paranasal tissue remodeling.

In summary, these data demonstrate that the cysLT2R expression on sinus eosinophils was higher in patients with CHS rather than those with NECS and controls. Furthermore, the increased cysLT2R mRNA expression was significantly correlated with the number of sinus eosinophils. These results suggest a possible role for cysLT2R in sinus diseases and may offer therapeutic benefits with the use of cysLT2R antagonists in these CHS patients. Further studies will be necessary to address these issues.

\section{References}

1. Albu, S., Tomescu, E., Mexca, Z., Nistor, S., Necula, S. and Cozlean, A. (2004) Recurrence rates in endonasal surgery for polyposis. Acta Otorhinolaryngol. Belg. 58; 79-86.

2. Beller, T. C., Maekawa, A., Friend, D. S., Austen, K. F. and Kanaoka, Y. (2004) Targeted gene disruption reveals the role of the cysteinyl leukotriene 2 receptor in increased vascular permeability and in bleomycin-induced pulmonary fibrosis in mice. $J$. Biol. Chem. 279; 46129-46134.

3. Capra, V., Ambrosio, M., Riccioni, G. and Rovati, G. E. (2006) Cysteinyl-leukotriene receptor antagonists: present situation and future opportunities. Curr. Med. Chem. 13; 3213-3226.

4. Corrigan, C., Mallett, K., Ying, S., Roberts, D., Parikh, A. and Scadding, G. (2005) Expression of the cysteinyl leukotriene receptors cysLT(1) and cysLT(2) in aspirin-sensitive and aspirintolerant chronic rhinosinusitis. J. Allergy Clin. Immunol. 115; 316-322.

5. Darwanto, A., Kitazawa, R., Mori, K., Kondo, T. and Kitazawa, S. (2008) MeCP2 expression and promoter methylation of cyclin D1 gene are associated with cyclin D1 expression in developing rat epididymal duct. Acta Histochem. Cytochem. 41; 135-142.

6. Ferguson, B. J. (2004) Categorization of eosinophilic chronic rhinosinusitis. Curr. Opin. Otolaryngol. Head Neck Surg. 12; $237-242$

7. Fujii, M., Tanaka, H. and Abe, S. (2005) Interferon-gamma up-regulates expression of cysteinyl leukotriene type 2 receptors on eosinophils in asthmatic patients. Chest $128 ; 3148-3155$.
8. Heise, C. E., O'Dowd, B. F., Figueroa, D. J., Sawyer, N., Nguyen, T. and Im, D. S. (2000) Characterization of the human cysteinyl leukotriene 2 receptor. J. Biol. Chem. 275; 30531-30536.

9. Higashi, N., Taniguchi, M., Mita, H., Kawagishi, Y., Ishii, T. and Higashi, A. (2004) Clinical features of asthmatic patients with increased urinary leukotriene E4 excretion (hyperleukotrienuria): Involvement of chronic hyperplastic rhinosinusitis with nasal polyposis. J. Allergy Clin. Immunol. 113; 277-283.

10. Iikura, M., Suzukawa, M., Yamaguchi, M., Sekiya, T., Komiya, A. and Yoshimura-Uchiyama, C. (2005) 5-Lipoxygenase products regulate basophil functions: 5-Oxo-ETE elicits migration, and leukotriene $\mathrm{B}(4)$ induces degranulation. J. Allergy Clin. Immunol. 116; 578-585.

11. Kanaoka, Y. and Boyce, J. A. (2004) Cysteinyl leukotrienes and their receptors: cellular distribution and function in immune and inflammatory responses. J. Immunol. 173; 1503-1510.

12. Kawate, T., Kawamura, R., Uchida, T., Takahashi, K., Hasegawa, T., Futamata, H., Katoh, R. and Takeda, S. (2009) Histochemical analysis of renal dysplasia with ureteral atresia. Acta Histochem. Cytochem. 42; 65-71.

13. Kieff, D. A. and Busaba, N. Y. (2005) Efficacy of montelukast in the treatment of nasal polyposis. Ann. Otol. Rhinol. Laryngol. 114; 941-945.

14. Livak, K. J. and Schmittgen, T. D. (2001) Analysis of relative gene expression data using real-time quantitative PCR and the 2(-Delta Delta C(T)) Method. Methods 25; 402-408.

15. Lynch, K. R., O'Neill, G. P., Liu, Q., Im, D. S., Sawyer, N. and Metters, K. M. (1999) Characterization of the human cysteinyl leukotriene CysLT1 receptor. Nature 399; 789-793.

16. Mita, H., Hasegawa, M., Saito, H. and Akiyama, K. (2001) Levels of cysteinyl leukotriene receptor mRNA in human peripheral leucocytes: significantly higher expression of cysteinyl leukotriene receptor $2 \mathrm{mRNA}$ in eosinophils. Clin. Exp. Allergy $31 ; 1714-1723$.

17. Murai, A., Abe, M., Hayashi, Y., Sakata, N., Katsuragi, T. and Tanaka, K. (2005) Comparison study between the mechanisms of allergic asthma amelioration by a cysteinyl-leukotriene type 1 receptor antagonist montelukast and methylprednisolone. $J$. Pharmacol. Exp. Ther. 312; 432-440.

18. Nelson, H. S. (2006) Advances in upper airway diseases and allergen immunotherapy. J. Allergy Clin. Immunol. 117; 10471053.

19. Ragab, S., Parikh, A., Darby, Y. C. and Scadding, G. K. (2001) An open audit of montelukast, a leukotriene receptor antagonist, in nasal polyposis associated with asthma. Clin. Exp. Allergy 31; 1385-1391.

20. Sarau, H. M., Ames, R. S., Chambers, J., Ellis, C., Elshourbagy, N. and Foley, J. J. (1999) Identification, molecular cloning, expression, and characterization of a cysteinyl leukotriene receptor. Mol. Pharmacol. 56; 657-663.

21. Shirasaki, H., Kanaizumi, E., Watanabe, K., Matsui, T., Sato, J. and Narita, S. (2002) Expression and localization of the cysteinyl leukotriene 1 receptor in human nasal mucosa. Clin. Exp. Allergy 32; 1007-1012.

22. Sousa, A. R., Parikh, A., Scadding, G., Corrigan, C. J. and Lee, T. H. (2002) Leukotriene-receptor expression on nasal mucosal inflammatory cells in aspirin-sensitive rhinosinusitis. N. Engl. J. Med. 347; 1493-1499.

23. Steinke, J. W., Bradley, D., Arango, P., Crouse, C. D., Frierson, H. and Kountakis, S. E. (2003) Cysteinyl leukotriene expression in chronic hyperplastic sinusitis-nasal polyposis: importance to eosinophilia and asthma. J. Allergy Clin. Immunol. 111;342-349.

24. Takasaki, J., Kamohara, M., Matsumoto, M., Saito, T., Sugimoto, T. and Ohishi, T. (2000) The molecular characterization and tissue distribution of the human cysteinyl leukotriene CysLT(2) receptor. Biochem. Biophys. Res. Commun. 274; 316-322.

This is an open access article distributed under the Creative Commons Attribution License, which permits unrestricted use, distribution, and reproduction in any medium, provided the original work is properly cited. 